\title{
Educação Superior e Trabalho em Santa Catarina: um enfoque nas carreiras de aplicação direta de ciência e tecnologia - STEM ${ }^{1}$
}

\author{
Tertiary education and work in Santa Catarina: a focus on the STEM careers
}

\author{
Carolina Custodio \\ carolinafcustodio@gmail.com \\ Universidade do Estado de Santa Catarina (UDESC)

\section{Patricia Bonini} \\ patriciabonini@gmail.com \\ Universidade do Estado de Santa Catarina (UDESC)
}

Resumo: Este artigo apresenta o perfil de carreiras e gênero dos cursos de graduação e emprego em Santa Catarina, destacando as áreas de formação de aplicação direta de ciência e tecnologia, agrupados no acrônimo STEM (Science, Technology, Engeneering and Mathematics). Estabelece-se uma correspondência entre os códigos da CBO (Classificação Brasileira de Ocupações) e o grupo de carreiras STEM, conforme definido pelo Departamento de Comércio Americano. As mulheres são 32\% dos ingressantes nos cursos STEM, apesar de serem $56 \%$ do total de ingressantes. As mulheres ocupam $21 \%$ dos empregos STEM, enquanto são $45 \%$ do total da força de trabalho. Estimando o prêmio STEM controlando para variáveis de idade, escolaridade e experiência, obtém-se que, na média do estado, as mulheres STEM ganham $64 \%$ a mais do que as Não STEM, um prêmio maior do que o dos homens, que é de $62 \%$.

Palavras-chave: Ensino superior; Diferenciais Salariais; Ciência e Tecnologia

\begin{abstract}
This article presents the gender profile of undergraduate courses in Santa Catarina, highlighting the STEM (Science, Technology, Engineering and Mathematics) careers. In addition, in order to describe the STEM labor force, we establish a correspondence between the Brazilian CBO (Classificação Brasileira de Ocupações) codes and the STEM group of careers defined according to the US Department of Commerce - ESA (Economics and Statistics Administration). At the university, women are 32\% of the students entering in STEM courses, despite being $56 \%$ of the total incomings. Women hold $21 \%$ of the STEM jobs, although they fill $45 \%$ of all jobs. Controlling for pruductivity variables, such as age, scholarly and experience, on average, in Santa Catarina, women in STEM jobs earn 64\% more than women in non STEM jobs, while men in STEM job earn $62 \%$ more than men in non STEM jobs.
\end{abstract}

Keywords: Higher education; Wage Differential; Science and Technology

Recebido em: 05-08-2018. Aceito em: 21-11-2018.

\section{INTRODUÇÃO}

\footnotetext{
${ }^{1}$ As autoras agradecem ao apoio da FAPESC, que financia o projeto de pesquisa que deu origem ao presente artigo
} 
A moderna teoria do crescimento econômico prognostica que a capacidade das nações de gerar prosperidade material progressivamente - ou seja, o crescimento sustentado - é determinada pela capacidade da força de trabalho de gerar e de aprender a lidar com novas tecnologias. Por sua vez, tal capacidade resulta do acúmulo de capital humano, na forma de educação e de treinamento no trabalho, como argumenta teoricamente Romer (1990) e BarroLee (2000) em um tratamento empírico.

Justificam-se, então, duas fortes tendências, sobre as quais repousa o foco deste artigo, observadas mundialmente. A primeira é o persistente crescimento da demanda mundial por educação em nível terciário, apesar de a população em idade entre 18 e 22 anos estar estável nos países desenvolvidos ou crescer apenas marginalmente, nos países em desenvolvimento. Em parte, esse persistente crescimento decorre de um fenômeno ainda em curso em muitos países, que é a convergência de capital humano entre gênero. A segunda tendência é a preocupação, por parte de governantes e administradores, com a educação e o trabalho nas atividades de aplicação direta de ciência e tecnologia, porque são atividades que rendem os melhores frutos em termos de crescimento econômico. Essas atividades têm sido agrupadas, nos países da Organização para a Cooperação e Desenvolvimento Econômico (OCDE), no acrônimo STEM - (Science, Technology, Engeneering and Mathematics) - definição dada, por exemplo, por Langdon (2014) e por Acola (2013) para uma comparação internacional. As economias fortemente baseadas nas atividades STEM apresentam um melhor desempenho em diversos indicadores econômicos e em termos de inovação e criação de empregos. As taxas de emprego, de patentes registradas, de salários e até mesmo de exportações são mais elevadas nessas economias (ROTHWELL, 2013).

A literatura tem reportado algumas características da força de trabalho STEM. A primeira é o crescimento persistente da demanda por esses trabalhadores em ritmo mais intenso do que o aumento da demanda pelos por trabalhadores nas demais áreas. Esse crescimento forte tem garantido aos profissionais com qualificação nas STEM maior média salarial do que o restante do mercado de trabalho, vantagem esta que tem sido chamada de prêmio salarial STEM. Uma segunda característica, generalizadamente observada, é a reduzida participação feminina nas atividades STEM. Uma terceira característica é que o prêmio STEM das mulheres é maior do que o dos homens, o que implica que o gap salarial entre homens e mulheres que atuam na força de trabalho STEM é menor do que na média do mercado de trabalho (BEEDE, 2013). Em algumas ocupações STEM, nos Estados Unidos, a desvantagem feminina é, de fato, revertida (GOLDBERG; HILL, 2007). 
O objetivo desse artigo $^{2}$ é apresentar um estudo sobre a oferta de cursos de nível superior em Santa Catarina que correspondem à denominação STEM e sobre a força de trabalho STEM no Estado de Santa Catarina. Investiga-se o modo como as mulheres atuam nos cursos de formação STEM, bem como nos postos de trabalho STEM. Destaca-se que a participação feminina no ensino superior, apesar de ultrapassar a masculina, distribui-se heterogeneamente pelas áreas do conhecimento, configurando uma sub-representação das mulheres no conjunto de carreiras STEM. Correspondentemente, as mulheres apresentam reduzida atuação na força de trabalho STEM. Paralelamente, objetiva-se investigar se a vantagem salarial STEM é maior para as mulheres do que para os homens, como tem sido observado nos Estados Unidos, por exemplo. Para tanto, são utilizados dados secundários coletados do censo universitário Instituto Nacional de Estudos e Pesquisas Educacionais Anísio Teixeira (INEP), para ensino, e da base Relação Anual de Informações Sociais (RAIS), para mercado de trabalho, ambos para o ano de 2015.

$\mathrm{O}$ artigo se organiza em cinco seções. Na próxima seção, contextualiza-se a temática STEM em termos especialmente da reduzida participação feminina. $\mathrm{Na}$ seção três, é esclarecida a metodologia do trabalho. Na seção quatro, apresentam-se os resultados sobre ensino e trabalho. A seção cinco traz as conclusões.

\section{CONTEXTUALIZAÇÃO: EDUCAÇÃO E TRABALHO}

A convergência de capital humano entre homens e mulheres é um fenômeno que está ainda em curso nos países não ocidentais e está praticamente terminada nos países ocidentais, incluindo aqueles ainda em desenvolvimento. Nos Estados Unidos e na Europa ocidental, essa convergência começou na década de 1960 e terminou no início dos anos 2010, quando mais de $50 \%$ dos concluintes dos cursos de graduação já eram mulheres (RESTUCCIA; VANDENBROUCKE, 2010).

Nos países em desenvolvimento, o Brasil é líder em termos da velocidade com que essa convergência ocorreu a partir dos anos 1960. Em 2001, as mulheres já representavam $56,3 \%$ do total dos alunos matriculados e $62,4 \%$ do total de alunos que concluíram o ensino universitário. Segundo Euromonitor (2018), em 2017, o Brasil emparelha com a Itália e Austrália, com a maior taxa de participação feminina na universidade, correspondente a 57\%

\footnotetext{
${ }^{2} \mathrm{O}$ presente artigo é derivado de projeto de pesquisa que tem como fonte de financiamento a Fundação de Amparo à Pesquisa e Inovação do Estado de Santa Catarina (FAPESC).
} 
dos registros. A média global é de $52 \%$, porque em países como Japão e Coreia do Sul as taxas de matrícula feminina na universidade são, respectivamente, 47\% e 40\%.

A convergência de capital humano entre os sexos é parte de mudança na estrutura socioeconômica causada pelo exercício de atividade econômica por parte das mulheres. Em Goldin (2006) são estabelecidas as etapas desse processo, que se iniciou ainda no final do século XIX e resultou numa "revolução silenciosa" ainda em curso nos dias atuais. A entrada das mulheres na força economicamente produtiva, inicialmente, teve caráter predominantemente econômico, à medida que o trabalho feminino era exercido em atividades de baixa qualificação e remuneração. Constituía, assim, apenas um acréscimo de renda familiar e correspondente acréscimo do PIB do país.

À medida que a população feminina também buscava melhor capacitação, passou a engrossar o contingente de matrículas nas universidades americanas e, subsequentemente, europeias. Esse fenômeno significou que a entrada das mulheres na força economicamente produtiva das nações seria uma mudança que ultrapassaria a esfera econômica. De fato, as mulheres puderam ampliar seus horizontes de escolha, redesenhar seu papel nos domínios público e privado e se habilitaram a tomar decisões, tanto na esfera pessoal quanto no ambiente de trabalho.

Embora não haja nenhuma forma aparente de incentivo ou coerção, as escolhas das jovens resultam numa especialização por gênero na universidade e no mercado de trabalho. As mulheres se afastam de algumas áreas técnicas, tais como engenharias e computação, enquanto os homens se afastam de carreiras tradicionalmente femininas, como pedagogia e nutrição.

Como reflexo das escolhas de cursos universitários, a ocupação dos postos de trabalho por parte das mulheres também ocorre de maneira heterogênea (GOLDIN, 2006; GIUBERTI, 2005; MENESES-FILHO, 2005). Especificamente, as mulheres apresentam participação no grupo de ocupações STEM bastante abaixo da média do mercado como um todo. Essa postura tem motivado órgãos governamentais e empresas a procurar mecanismos para tentar atrair a população feminina para essas áreas.

Nos EUA e países da OCDE, tomados em conjunto, aponta-se que as mulheres ocupam menos de $25 \%$ dos empregos STEM. Porém, as mulheres nos empregos STEM ganham 33\% a mais do que a média das mulheres nos empregos Não STEM, um prêmio STEM maior do que o dos homens. (BEEDE., 2011). Assim, a superioridade do prêmio STEM feminino em relação ao masculino contribui para a convergência salarial de gênero. 
A maior procura por mão de obra qualificada em áreas STEM abrange não só trabalhadores altamente especializados como também aqueles com conhecimento mais geral de conceitos STEM. No caso brasileiro, esses trabalhadores detêm diplomas de cursos tecnológicos, que são cursos de menor duração quando comparados aos bacharelados, e destinados a pessoas que desejam ingressar mais depressa no mercado de trabalho.

\section{METODOLOGIA}

A descrição apresentada neste artigo resulta da organização dos dados provenientes de dois tipos de fontes: dados obtidos por meio do censo universitário - INEP - referentes ao ano de 2015, que permitiu a quantificação da população universitária do Estado de Santa Catarina e a identificação de todos os cursos de graduação no estado. Para o mercado de trabalho, foram acessados os microdados da RAIS (2015), disponibilizados pelo Ministério do Trabalho e Emprego (MTE). Todos os dados foram organizados de acordo com duas categorias, quais sejam, STEM e Não STEM. Dentro de cada uma destas, identificam-se ainda duas subcategorias, que são o sexo masculino e feminino.

O critério para agrupamento dos cursos universitários seguiu aquele utilizado nos bancos de dados da OCDE. Os dados do ensino superior são organizados em termos de áreas do conhecimento, com um subgrupo de “áreas específicas”. São 22 áreas específicas, das quais 8 são identificadas como cursos de formação STEM. Dentre as informações fornecidas pelo censo universitário do INEP, encontra-se a área específica a que pertence o curso do estudante. A Tabela 1 do Apêndice A deste artigo apresenta as áreas de conhecimento estabelecidas pela OCDE, onde são destacadas aquelas que compõem o grupo STEM - de 42 A 62 - bem como os cursos universitários que fazem parte desse conjunto STEM.

Observamos que a formação em carreiras universitárias STEM não corresponde necessariamente à atuação em posto de trabalho STEM. Por isso, os critérios para identificar um e outro não precisam ser exatamente iguais. Muitos indivíduos se formam em cursos de área STEM, mas não estão classificados como força de trabalho STEM.

O ponto de partida para categorizar os dados da RAIS foi a Classificação Brasileira de Ocupações $(\mathrm{CBO})^{3}$, uma vez que esta é enumerativa e inclui código, título ocupacional e uma breve descrição da ocupação. Complementarmente, a classificação descritiva específica as atividades realizadas no trabalho, os requisitos de formação e experiência profissionais e as

\footnotetext{
3 Cujo banco de dados do documento está à disposição da população para consulta pela internet em: http://www.ocupacoes.com.br/tabela-completa-da-cbo.
} 
condições de trabalho. A partir dessa descrição, o agrupamento das ocupações no conjunto definido como STEM foi feito com base no critério utilizado pelo órgão de estatística do governo americano Economics and Statistics Administration (ESA). São consideradas as ocupações de suporte profissional e técnico nos campos de ciências da computação, matemática, engenharias, ciências físicas e da terra (BEEDE, 2011) ${ }^{4}$.

Dentre as 2.511 ocupações CBO, foram identificados 164 códigos de ocupações que correspondem ao grupo STEM. O Quadro 1 do Apêndice B apresenta esses códigos. São códigos de apenas dois grandes grupos, o 1 e o 2. Do Grande Grupo 1, apenas os gerentes de apoio - 142, cujas famílias de ocupação contêm os gerentes de tecnologia da informação, correspondendo às ocupações de gerente de rede; gerente de desenvolvimento de sistemas, gerente de produção de Tecnologia da Informação; gerente de projetos de TI, Gerente de Segurança da TI, Tecnólogo de Gestão de TI.

Do Grande Grupo 2, que designa Profissionais de Ciências e das Artes, foram considerados 3 subgrupos principais: todas as subdivisões do subgrupo 20 (pesquisadores e profissionais policientíficos, todas as divisões do subgrupo principal 21 (Profissionais das Ciências Exatas, Física e da Engenharia) e ocupações do subgrupo principal 22 (agrônomos e afins).

Ressalta-se que, mesmo nos Estados Unidos, os profissionais de ensino não são incluídos no grupo STEM. Uma das razões é a dificuldade de se identificar, nos bancos de dados, as áreas específicas de atuação nas atividades de ensino, uma vez que um professor universitário de física está registrado como "professor universitário", por exemplo.

Para estimar o prêmio salarial STEM, os dados da RAIS foram ajustados a um seguinte modelo econométrico que se baseia nas modernas adaptações da metodologia de decomposição de Oaxaca - Oaxaca (1973) e Oaxaca e Ranson (1994), desenvolvida originalmente para comparação de médias salariais entre dois grupos de trabalhadores e identificação do impacto das variáveis explicativas de salário em cada um dos grupos. Emprega-se aqui a programação no software STATA ${ }^{\circledR}$, desenvolvida por Jann (2008), para decomposição de Oaxaca.

4 Não há perfeita homogeneidade em termos desse agrupamento de atividades nos órgãos de governo e pesquisa. Em termos mais gerais, consideram-se STEM as ciências da terra - excluindo-se o exercício das ciências médicas - as ciências físicas, matemática e estatística, computação e engenharias. Alguns órgãos governamentais incluem os gerentes da área de TI. Já a OCDE inclui ainda processos e manufatura e construção e arquitetura. As carreiras e ocupações que os órgãos do governo americano incluem no grupo STEM podem ser encontradas em http://nces.ed.gov/pubs2009/2009081.pdf 
Os dados são ajustados à seguinte equação:

$$
\ln y_{i}=\beta_{0}+\alpha_{0} D_{j}+x_{i} \beta+u_{i}
$$

em que ln y é o logaritmo do salário-hora de cada empregado, i; o termo $\beta_{0}$ é uma variável latente que representa a heterogeneidade não observada no modelo. $\mathrm{O}$ vetor $\mathrm{X}$ contém as variáveis explicativas, que são a escolaridade (em intervalos), o tempo de trabalho no último emprego (medido em meses), a idade dos trabalhadores (medida em anos), o sexo e ocupação (STEM e Não STEM). Além disso, inclui-se no modelo a idade ao quadrado para capturar o fato de que o retorno associado à idade apresenta retornos marginais decrescentes.

Assume-se que o termo de erro $u_{i}$ é estocástico, não autocorrelacionado e com variância constante, supondo ausência de correlação entre o erro e respectivo vetor explicativo $\mathrm{x}_{\mathrm{i}}, \mathrm{E}\left(\mathrm{u}_{\mathrm{i}} \mid \mathrm{x}_{\mathrm{i}}\right)=0$. Portanto, considera-se que as variáveis explicativas são exógenas. Para corrigir o problema de heterocedasticidade, comum a dados de amostras cross section, ajustamos a estimação robusta a erros de heterocedásticos, com correção pela matriz de White.

A escolaridade, idade e tempo no emprego são determinantes de produtividade, de acordo com a teoria do capital humano - Becker (1957). Estas são, portanto, variáveis de controle para estimativa do prêmio STEM. Assim, o coeficiente da variável dicotômica STEM/Não STEM indica em que medida a média salarial do grupo STEM é maior/menor do que a do grupo Não STEM, se ambos os grupos tivessem as mesmas caraterísticas de idade, escolaridade e tempo no emprego. Assim, o coeficiente de regressão estimado para a diferença de média salarial STEM/Não STEM pode ser interpretado como prêmio STEM. Esse coeficiente é estimado para os homens e para as mulheres separadamente, com o objetivo de investigar se ocorre em Santa Catarina a superioridade do prêmio STEM feminino.

Para a análise descritiva, a escolaridade do trabalhador foi dividida nos intervalos: menor do que ensino médio, ensino médio, ensino superior incompleto, ensino superior completo, e pós-graduação. Para a estimativa do prêmio STEM, utilizou-se, como base de comparação, o grau de escolaridade de ensino superior incompleto, com estimativas de coeficientes da contribuição do grau superior completo, mestrado e doutorado para a determinação da média salarial de cada grupo. 
O modelo é estimado para os dados de municípios catarinenses selecionados: Florianópolis, Blumenau, Criciúma, Joinville, Lages e Chapecó e para os dados do estado como um todo, SC. Embora fuja do objetivo deste artigo, os resultados das regressões são apresentados nas tabelas 02 e 03 do Apêndice, que podem ser interpretados como a contribuição de cada variável para a formação da média salarial do grupo. Como nosso interesse é a diferença entre o prêmio STEM masculino e feminino, ao longo da análise na seção 4.1, foca-se apenas no coeficiente dessa variável incluída no vetor $\mathrm{X}$ da equação (1) acima.

\section{ANÁLISE DESCRITIVA PARA ENSINO: STEM e Não STEM}

A caracterização da população universitária de Santa Catarina, em termos de graduação, é ilustrada na Tabela 1. Em 2015, estavam registrados 391.765 estudantes, sendo 56,5\% mulheres. Desses registros, 16\% eram concluintes em 2015 (67.274 estudantes) e 26,5\% eram ingressantes (103.858 estudantes). A parcela feminina dos concluintes em 2015 era de $66.5 \%$, e dentre os ingressantes, 55.7\%. Foram identificados 206 cursos de graduação, quando consideradas as diferenças entre habilitações em bacharelado, licenciatura e tecnológico. Os cursos STEM encontrados somam 69 e estão listados no Quadro 1 do Apêndice A.

Tabela 1 - População de estudantes nos cursos de graduação em $2015^{5}$

\begin{tabular}{|c|c|c|c|c|}
\hline & $\begin{array}{l}\text { Número de } \\
\text { estudantes }\end{array}$ & $\%$ feminina & $\begin{array}{c}\text { \% ensino médio } \\
\text { público }\end{array}$ & $\begin{array}{c}\text { \% ensino } \\
\text { médio privado }\end{array}$ \\
\hline Ingressantes & 103.858 & 55,7 & 68 & 32 \\
\hline Concluintes & 67.274 & 66,5 & 72 & 24 \\
\hline $\begin{array}{l}\text { Total de } \\
\text { registros }\end{array}$ & 391.765 & 56,5 & - & - \\
\hline
\end{tabular}

Fonte: Cálculo dos autores com base no censo INEP (2015).

Um aspecto interessante dessa população, embora sua discussão não faça parte do escopo deste artigo, diz respeito ao financiamento da educação de nível médio. A Tabela 01

\footnotetext{
${ }^{5}$ Há uma pequena percentagem de concluintes cujo tipo de escola frequentada no ensino médio não é identificado.
} 
ainda indica que a grande maioria dos concluintes e ingressantes frequentou ensino médio em escola pública. De fato, o ensino médio cursado pelos universitários é público para $68 \%$ dos ingressantes e $72 \%$ dos concluintes em 2015.

No que se segue, é analisada a distribuição dos cursos universitários e proporção de mulheres segundo áreas do conhecimento. No Gráfico da Figura 1, os cursos STEM pertencem às áreas 42 a 62.

Figura 1 - Porcentagem de mulheres nos cursos universitários de Santa Catarina por áreas da OCDE

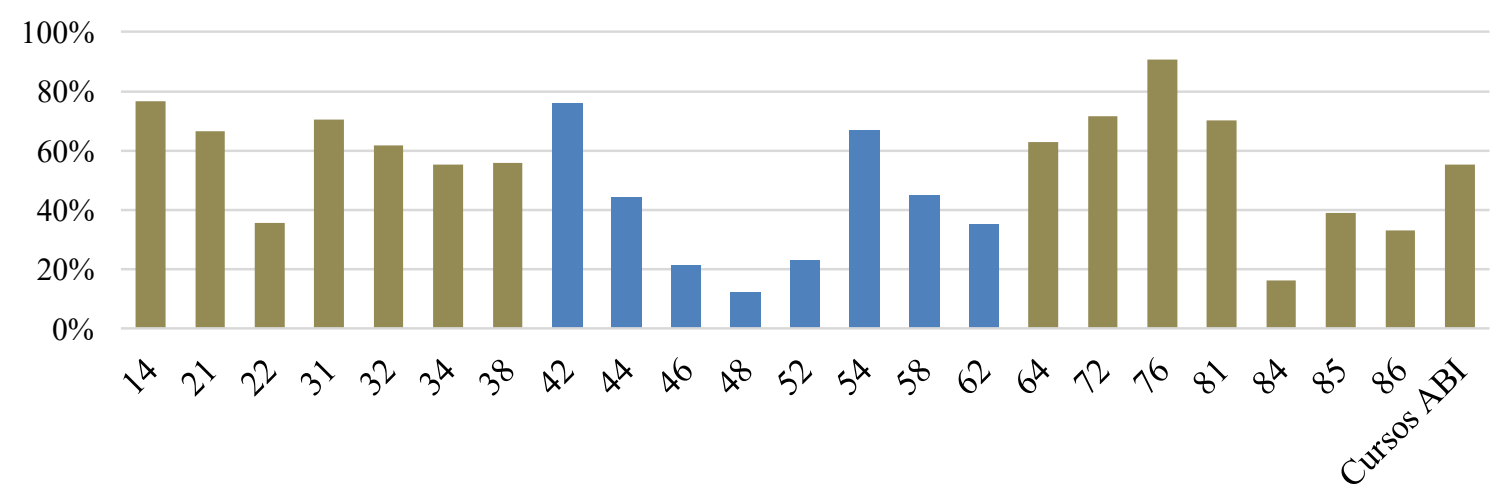

Códigos áreas OCDE

Fonte: cálculo próprio com base no banco de dados - INEP (2015).

A Figura 1 oferece, assim, uma visão mais ampla da heterogeneidade da participação das mulheres nos cursos universitários. O Quadro 1 do Apêndice A esclarece quais são as 22 áreas do conhecimento. Por exemplo, na área 14 classifica os cursos de "formação de professor e ciências da educação"; na área 76, "ciências sociais". Os cursos "ABI" são aqueles em que, no Brasil, o estudante deve optar, num dado ponto do curso, por "bacharelado" ou "licenciatura". As áreas 46, 48 e 52 agrupam os cursos, respectivamente, de matemática e estatística, computação, engenharias. Percebe-se que estas apresentam os menores índices de participação feminina. Já a Figura 2 mostra os cursos e seus perfis de gênero. 
Figura 2 - Perfil de gênero dos 30 maiores cursos de graduação em Santa Catarina: ingressantes e formandos em 2015

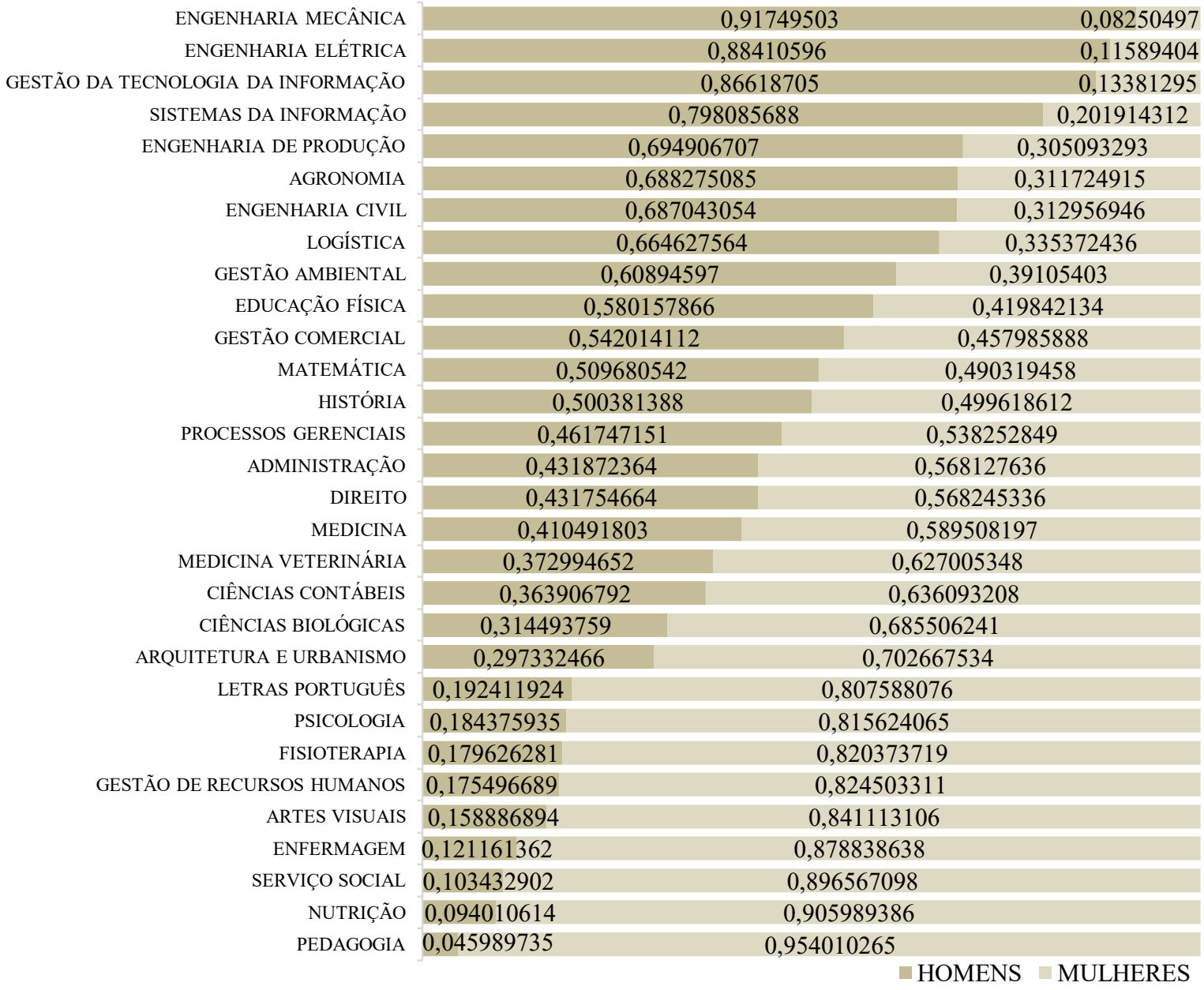

Fonte: cálculo próprio com base no banco de dados - INEP (2015).

Nesse caso, ficam mais evidentes as diferenças quanto às escolhas de carreira entre homens e mulheres. Na Figura 2, os cursos 1 a 30 estão em ordem crescente de participação feminina: pedagogia - curso 1 - tem 95\% de mulheres, seguida de nutrição e serviço social, com $91 \%$ e $90 \%$, respectivamente. A proporção de gênero se iguala no $18^{\circ}$ e $19^{\circ}$ cursos do ranking, que são os de história e matemática, respectivamente.

Os oito primeiros cursos da Figura 2 são caracterizados como STEM e são tipicamente escolhas masculinas. A partir do nono curso, na Figura 2, os cursos STEM são apenas o de matemática e ciências biológicas, que se destacam por apresentarem maiores representatividade feminina dentre as áreas STEM.

O curso de graduação em matemática - assim como física e química, que não aparecem na Figura 2 - apresentam maior participação feminina por serem cursos com possibilidade de 
habilitação em licenciatura, que capacita o formando a exercer atividades profissionais de ensino. Muitas mulheres com formação em cursos nas áreas STEM não trabalham em ocupações STEM, mas seguem carreiras relacionadas ao ensino.

Outro aspecto dos cursos universitários analisados é que os cursos tecnológicos STEM representam pequena proporção do total de estudantes. Além disso, a proporção STEM, dentre os cursos tecnológicos, também é bastante reduzida, como mostra o gráfico da Figura 3.

Figura 3 - Cursos STEM: habilitações em bacharelado e tecnológico em Santa Catarina

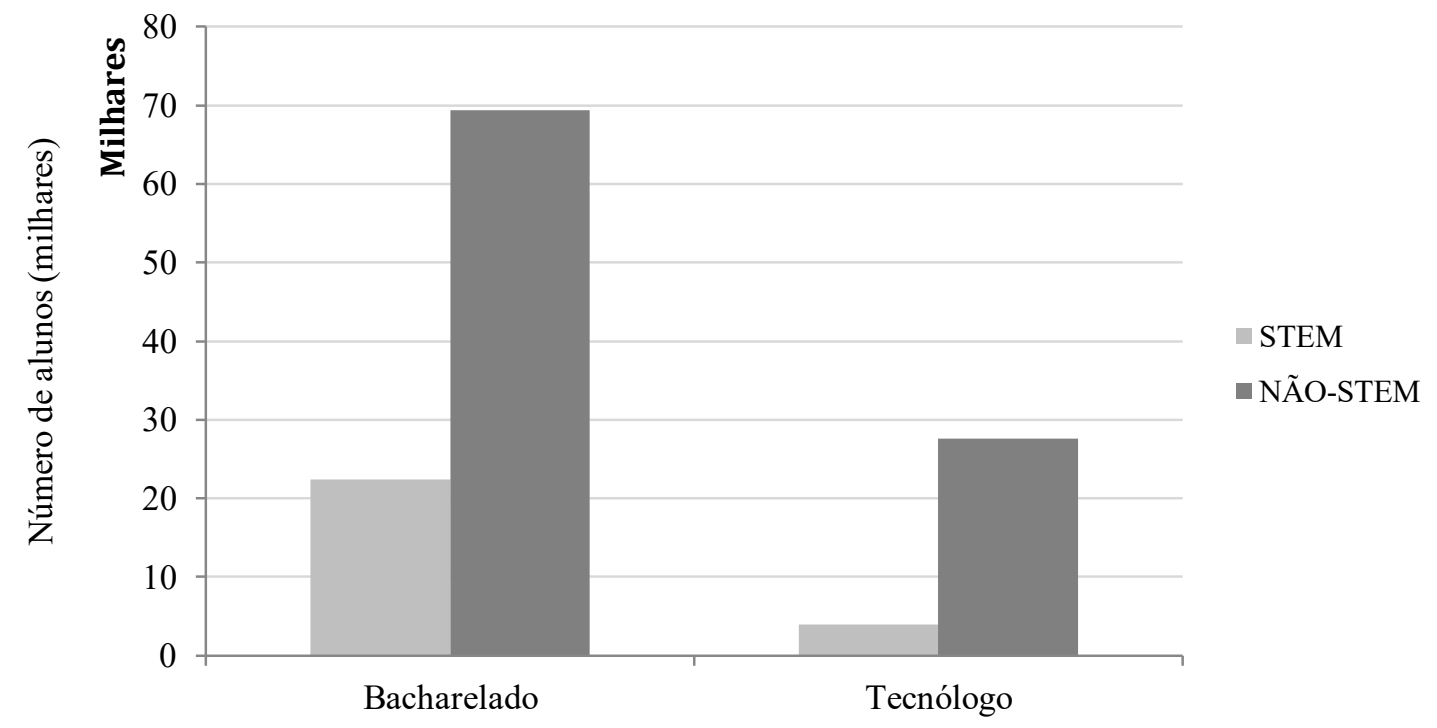

Fonte: cálculo próprio com base no banco de dados - INEP (2015).

De acordo com Rothwell (2013), nos Estados Unidos, a presença de trabalhadores com formação em nível técnico STEM na economia é responsável por mais de um quarto da inovação na produção. Além disso, a concentração destes empregos na economia contribui para reduzir a desigualdade de renda, uma vez que se trata de indivíduos que investem menos tempo na educação em nível superior e ao mesmo tempo auferirão médias salariais mais próximas a muitos grupos de trabalhadores com alto grau de investimento em capital humano ${ }^{6}$.

${ }^{6}$ Santa Catarina conta com 13 cursos desta modalidade (STEM-tecnológico), são estes: Análise de Desenvolvimento de Sistemas, Automação Industrial, Gestão da Tecnologia da Informação, Jogos Digitais, Manutenção Industrial, Mecatrônica Industrial, Processos Químicos, Radiologia, Redes de Computadores, Sistemas de Energia, Sistemas Eletrônicos, Sistemas para Internet e Web Design e Programação. O total de alunos no ano de 2015 pertencentes a esta categoria são 3.925, dos quaisapenas 569 são mulheres. 
O gráfico da Figura 4 ilustra as diferenças entre formação STEM e atuação nos postos de trabalho STEM e a reduzida representatividade feminina nas áreas STEM, tanto na universidade quanto no trabalho. Os trabalhadores registrados no mercado formal em 2015 totalizam 3.448.450, sendo que as mulheres correspondem a 45\%. As ocupações agrupadas como STEM correspondem a $0.88 \%$ do total do mercado de trabalho, e a participação feminina no grupo STEM é de $26 \%$. Assim, o perfil de gênero do grupo STEM no mercado de trabalho de Santa Catarina se assemelha ao americano, no qual as mulheres são cerca de $24 \%$ da força de trabalho STEM.

A participação STEM no trabalho é muito menor do que sua correspondente na universidade, que totaliza $22 \%$ dos ingressantes e $15 \%$ dos concluintes. Uma explicação para essa diferença se encontra no fato de que formação é diferente de ocupação.

Como ocorre nos demais países, especialmente nos Estados Unidos, muitas pessoas têm formação nas carreiras STEM, mas não exercem atividade laboral STEM. Por exemplo, os empregos nas áreas de ensino não são STEM. Muitos cursos universitários em áreas do grupo STEM, como, matemática, física e química, oferecem habilitações em licenciatura e bacharelado. Nesse último caso, os formados poderão exercer atividades de ensino. Professores universitários também não estão incluídos no grupo STEM do mercado de trabalho.

Figura 4 - Representatividade STEM em Santa Catarina: ensino e trabalho

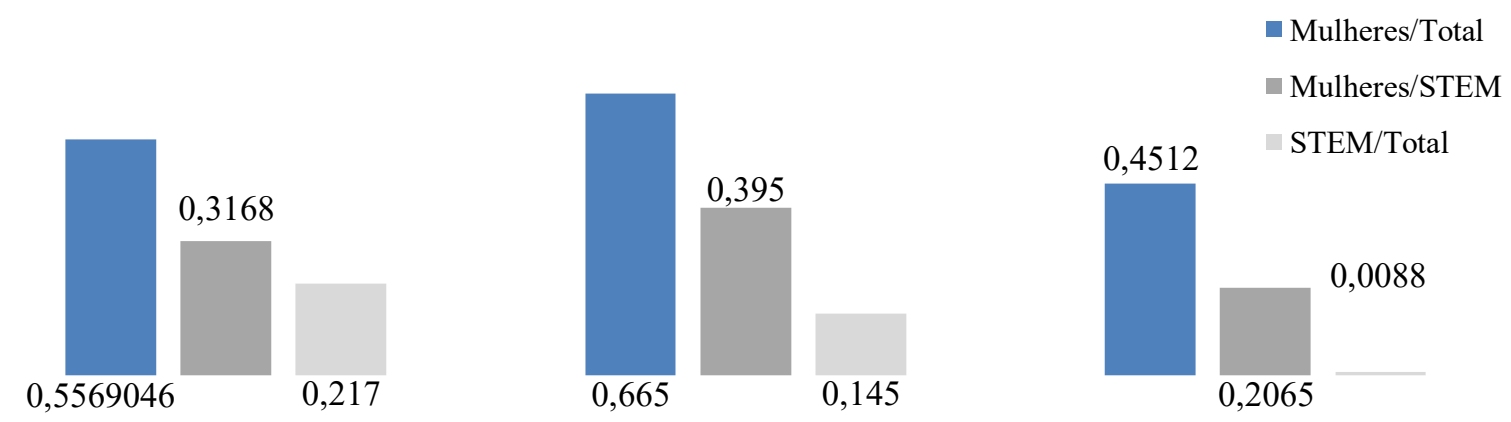

Fonte: cálculo próprio com base no banco de dados da RAIS (2015) e INEP (2015).

Uma segunda linha de explicação para a discrepância quanto à proporção STEM na universidade e no mercado de trabalho decorre da simultaneidade inerente aos dados. Trata-se de formação universitária e atuação laboral num dado ponto no tempo. Supostamente, os concluintes de 2015 atuarão em postos de trabalho nos anos subsequentes. Dada a grande diferença de proporções, pode-se intuir que a discrepância entre as proporções de concluintes 
STEM na universidade e de trabalhadores STEM no mercado indique a percepção de uma crescente demanda por pessoas com esse tipo de qualificação.

\subsection{ANÁLISE DO TRABALHO STEM EM SANTA CATARINA}

Em termos internacionais, a força de trabalho STEM, nos Estados Unidos, por exemplo, representa cerca de $5 \%$ do total, e as mulheres são apenas $24 \%$ do trabalho STEM (BEEDE, 2011). Os dados encontrados para o Brasil, a partir da RAIS, indicam que nossa força de trabalho STEM é $1.19 \%$ do total e que as atividades STEM não estão homogeneamente no território nacional. O gráfico à esquerda da Figura 5 ilustra o quanto o trabalho STEM representa no total em cada grande região brasileira.

Nas regiões sul e centro oeste, o trabalho STEM representa cerca de $1 \%$ do total do mercado, o que é bem próximo da média nacional de $1.19 \%$. Já as regiões norte e nordeste apresentam proporções STEM da força de trabalho menores do que $1 \%$, sendo a região norte aquela que apresenta menor proporção da força de trabalho atuando em postos de trabalho STEM. A região Sudeste possui a maior proporção STEM da força de trabalho, com mais de $1.5 \%$ dos trabalhadores atuando em atividades nas áreas STEM. Já a região norte possui apenas $0.4 \%$ de sua força de trabalho atuando nas áreas STEM. Considerando que a população empregada na região Sudeste é muito maior do que na região Norte, percebe-se uma grande concentração dessas atividades na região Sudeste

Comparando as Figuras 4 e 5, então, percebe-se que o Estado de Santa Catarina apresenta participação feminina na força de trabalho STEM abaixo da média de sua região. 
Figura 5 - Participação regional STEM e Enfoque no trabalho STEM

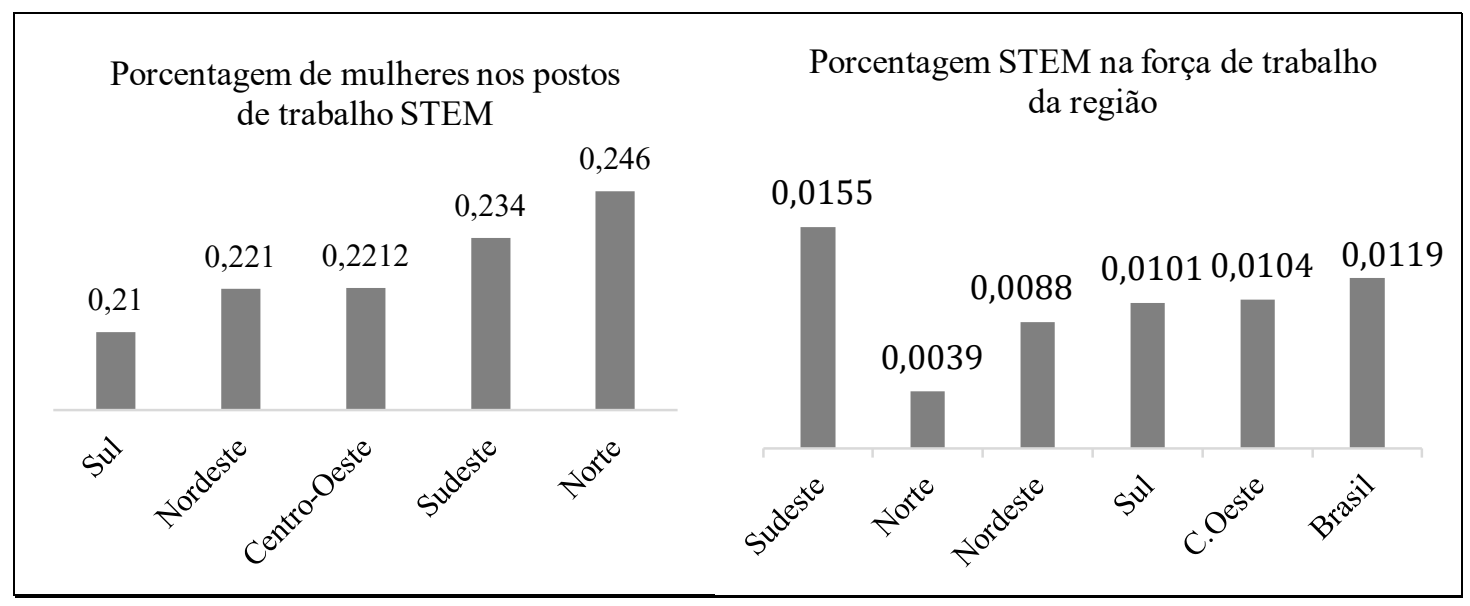

Fonte: cálculo próprio com base no banco de dados da RAIS (2015).

Já a representatividade feminina na força de trabalho STEM, em termos de cada grande região, fica entre $21 \%$ e 24,6\%, como ilustrado no gráfico à direita, na Figura 5. A Região Norte apresenta a maior participação feminina no seu grupo STEM, enquanto a Região Sul, a menor participação.

Um fato amplamente observado nas economias da OCDE é que a força de trabalho STEM apresenta escolaridade maior do que a média dos demais trabalhadores. O gráfico da Figura 6 mostra que este é também o caso em Santa Catarina.

Verifica-se que cerca de $82 \%$ de homens e mulheres STEM têm nível superior completo, contra apenas $9.6 \%$ e $20.1 \%$, respectivamente, de homens e mulheres Não STEM. 
Figura 6 - Escolaridade nas áreas STEM e Não STEM por gênero em Santa Catarina

$\square$ Pós-graduação $\square$ Superior completo $\square$ Superior incompleto $\square$ Ensino médio $\square$ Menor-médio
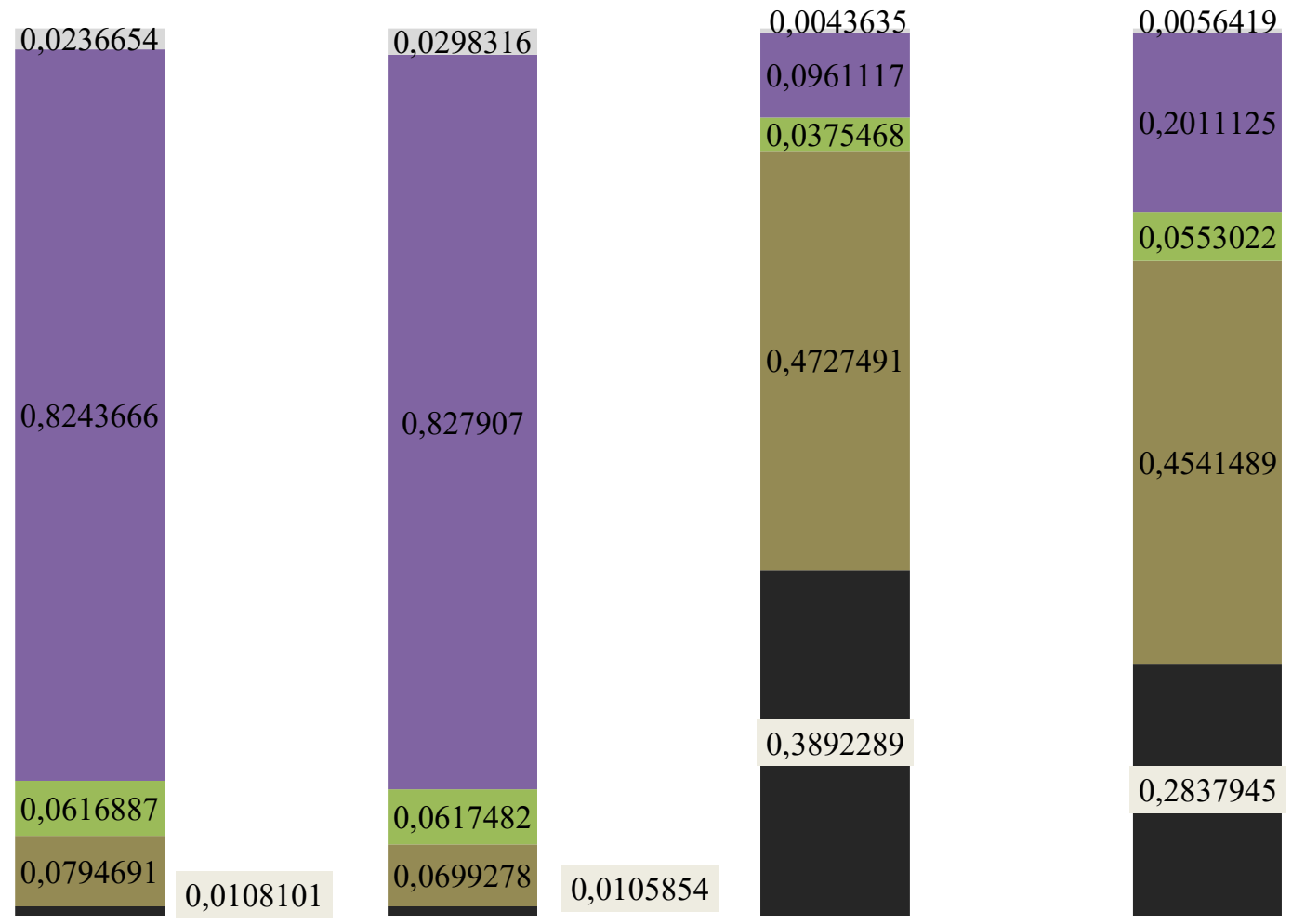

Fonte: cálculo próprio com base na RAIS - 2015.

Por fim, vale destacar que em ambos os grupos, STEM e Não STEM, as mulheres apresentam maior média de escolaridade. Em especial, destaca-se que, no grupo Não-STEM, a proporção de mulheres com escolaridade maior ou igual a de nível superior completo é o dobro da proporção de homens com essa escolaridade.

Em termos das regiões do Estado de Santa Catarina, o gráfico da Figura 7 ilustra que Florianópolis, Blumenau e Joinville são, de fato, polos tecnológicos, com alta representatividade STEM em sua força de trabalho. 
Figura 7 - Força de trabalho STEM e média salarial

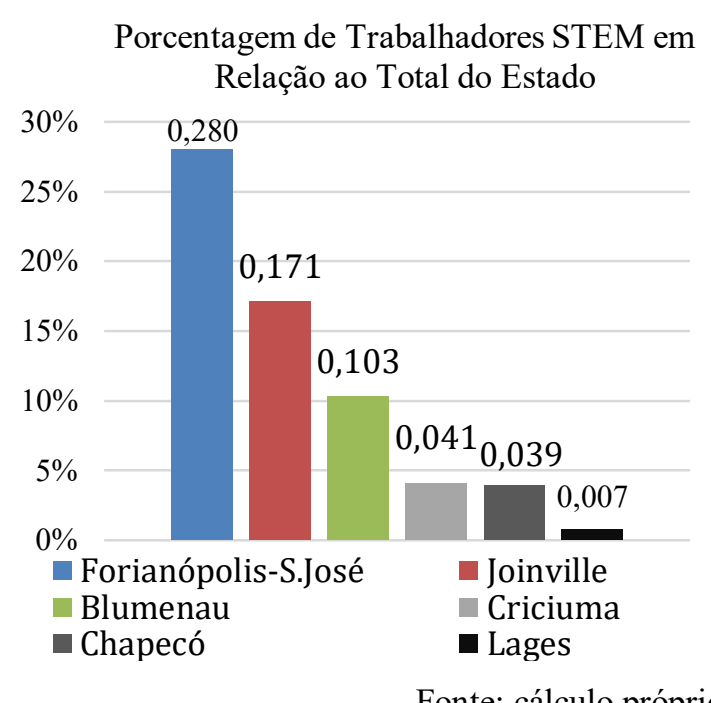

Salário-Hora Médio: STEM e Não STEM

$\mathrm{R} \$ 250$

$\mathrm{R} \$ 200$

$\mathrm{R} \$ 150$

$\mathrm{R} \$ 100$

$\mathrm{R} \$ 50$

$\mathrm{R} \$ 0$

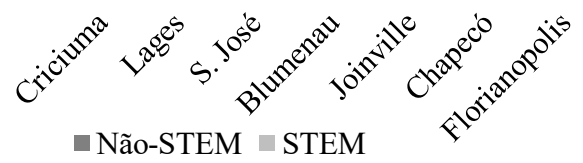

Fonte: cálculo próprio com base na RAIS - 2015.

Florianópolis, por exemplo, tem, em sua maioria, empresas de pequeno e médio portes de software e serviços, destacando-se no segmento de hardware e outros equipamentos de alta tecnologia. Além disso, há também incubadoras de empresas de base tecnológica, fatores estes que estão diretamente ligados às universidades, uma vez que estas instituições são responsáveis pela formação de grande parte da mão de obra especializada e que, além do ensino, lideram pesquisas. Já Blumenau atribui a origem do segmento tecnológico à forte indústria do setor têxtil. Conhecida como vale do software, a Região de Blumenau se destaca também por promover integração das etapas criativas e produtivas, características deste setor. Assim como Blumenau, o polo tecnológico em Joinville se associa à presença de grandes indústrias, principalmente as do segmento metal mecânico e têxtil.

O município de Lages não apresenta perfil de polo tecnológico, com representatividade STEM em sua força de trabalho igual à média do estado, 0.88\%. Já Criciúma e Chapecó são polos tecnológicos menos consolidados, mas que estão crescendo nessa direção. Ressalta-se que, juntamente com Blumenau e Florianópolis, Criciúma e Chapecó contam com leis de incentivo à inovação em vigor. Estas leis dispõem sobre medidas de fomento à inovação e à pesquisa científica e tecnológica no ambiente produtivo. Dispõem ainda sobre a criação de conselhos e fundos municipais de ciência, tecnologia e inovação, de modo a fortalecer e incentivar o ecossistema de inovação.

O lado direito da Figura 7 mostra a comparação entre as médias salariais do grupo STEM com o Não STEM em alguns municípios estudados. A maior média salarial STEM ocorre em Florianópolis, mas o maior diferencial entre STEM e Não STEM parece estar em 
Lages, que não se caracteriza por ser polo tecnológico. No entanto, uma análise estatística desses diferenciais salariais requer um certo controle das características dos trabalhadores que influenciam sua produtividade, tais como idade, tempo no emprego e escolaridade. No que se segue, apresentamos os resultados da comparação entre as médias salariais dos grupos STEM e Não STEM, controlando essas variáveis de produtividade.

\subsubsection{Estimativa do prêmio STEM para homens e mulheres.}

Nesta seção, o grau de escolaridade do empregado, a idade e o tempo no emprego são tratados como variáveis de controle para estimativa dos diferenciais salariais entre os trabalhadores STEM e Não STEM em alguns municípios selecionados. Assim, o modelo da equação (1), da seção 3, é ajustado aos dados da RAIS para estimar o prêmio STEM, sendo a ocupação numa atividade do grupo STEM uma variável dicotômica.

O grupo tomado como base de comparação é o homem Não STEM. Os coeficientes das regressões estimadas para homens e mulheres são apresentados nas tabelas 2 e 3 do Apêndice C. Todos os coeficientes são estatisticamente significativos, em nível de significância de 1\%.

O gráfico da Figura 8 ilustra a interpretação dos coeficientes de regressão da Tabela 1, do apêndice C. O prêmio STEM médio das mulheres que trabalham em Santa Catarina é de $64 \%$ e o dos homens, $62 \%$. Em Joinville e Chapecó, o prêmio STEM das mulheres também é maior do que o dos homens, sendo que em Chapecó ocorre as maiores distâncias entre os prêmios feminino e masculino. Em Chapecó, em média, a mulher que atua num emprego STEM recebe $70 \%$ a mais do que uma mulher com as mesmas características de idade, escolaridade e experiência no emprego, que atua num emprego Não STEM. Já o prêmio STEM dos homens é de $30 \%$. 
Figura 8 - Prêmio salarial STEM baseado na análise de regressão para Santa Catarina $2016^{7}$.

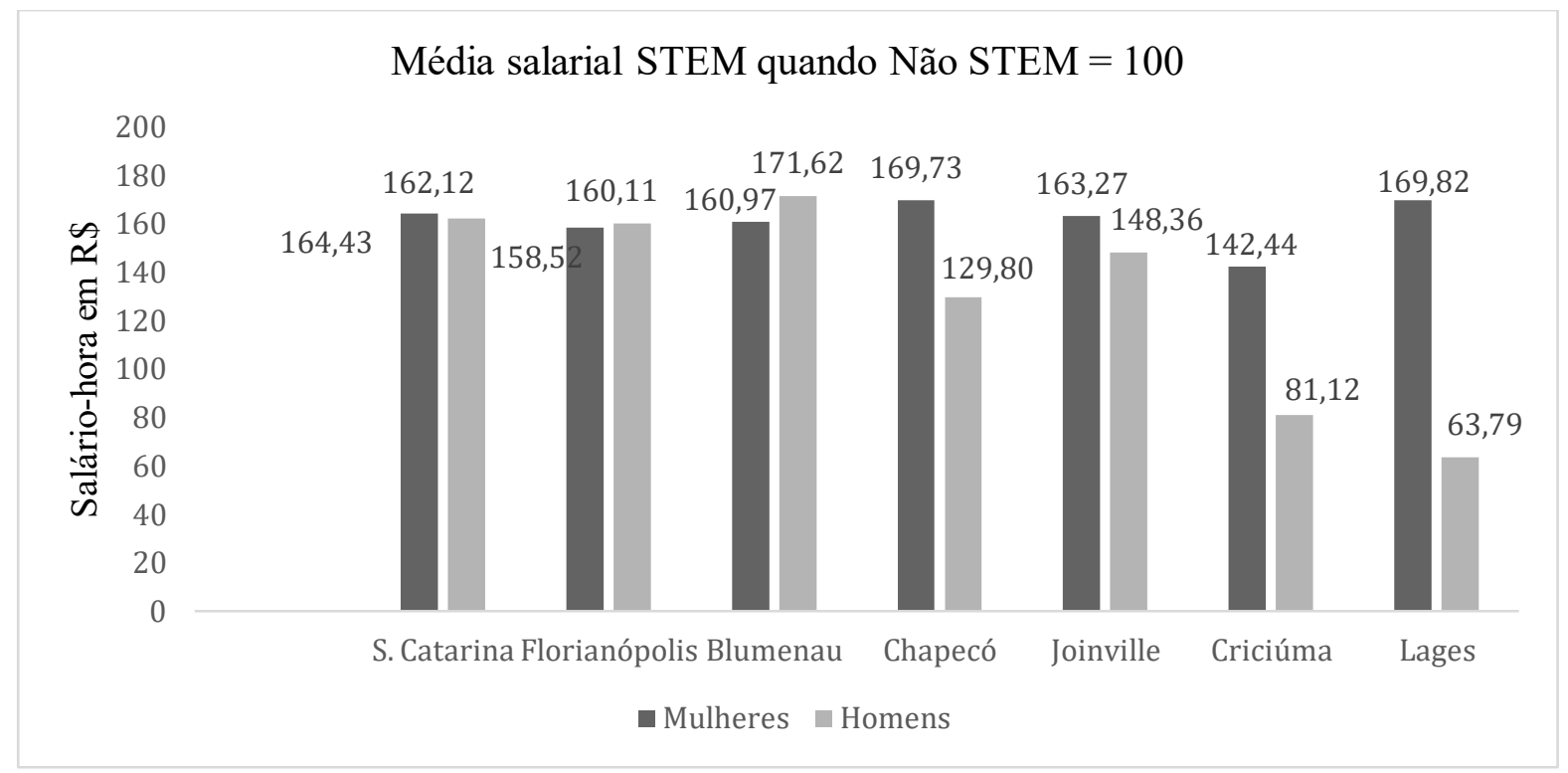

Fonte: cálculo próprio com base na RAIS - 2015.

O maior prêmio STEM ocorre em Blumenau, sendo $72 \%$ para os homens. Esse município é o terceiro maior polo tecnológico do estado, com $10.3 \%$ da força de trabalho STEM do Estado, como mostra a Figura 7. O segundo maior prêmio do estado é de $70 \%$ e ocorre para as mulheres de Chapecó e de Lages, que, por sua vez, são municípios de pequena representatividade STEM em sua força de trabalho. Assim, uma comparação inter-regional da magnitude do prêmio STEM sugere que o peso desse setor na atividade da economia regional não necessariamente determina a vantagem salarial do grupo STEM.

Num outro extremo estão os homens de Chapecó, Criciúma e Lages. Os homens de Chapecó recebem o menor prêmio STEM, e em Criciúma e Lages os homens do grupo STEM têm média salarial inferior à média dos homens Não STEM. Mantidos constantes idade, escolaridade e tempo no emprego, em Lages, um homem que esteja trabalhando num emprego STEM tem salário 36\% menor do que um homem que trabalha em empregos Não STEM. Em Criciúma, essa desvantagem dos homens STEM é de 18\%.

Em Lages, Chapecó e Criciúma também ocorrem as maiores distâncias entre prêmios em termos de gêneros. Nesses municípios, a atuação profissional numa carreira STEM é muito mais vantajosa para as mulheres do que para os homens. Em Chapecó, o salário dos

${ }^{7} \mathrm{O}$ gráfico mostra a interpretação dos coeficientes de regressão estimados e mostrados na Tabela 1 do Apêndice C. 
homens STEM é 30\% maior do que o dos homens Não STEM, enquanto a média salarial das mulheres STEM é 70\% maior do que as mulheres Não STEM.

\section{CONSIDERAÇÕES FINAIS}

Este artigo apresentou uma descrição de alguns aspectos do mercado de trabalho de Santa Catarina, bem como da oferta de cursos de formação de nível terciário. Os aspectos considerados se referem à sub-representação feminina e ao prêmio salarial que ocorrem nas áreas de formação e atuação profissional STEM. Trata-se de profissionais que determinam a capacidade de criação e difusão de novas tecnologias nas economias modernas, e as mulheres têm participado de forma limitada tanto em termos de formação quanto em termos de atuação profissional. Tal sub-representação mostra possível perda de talento numa área importante para a economia.

A partir de dados sobre ensino e mercado de trabalho no Estado, foi constatado que Santa Catarina - ou mesmo o Brasil e suas grandes regiões - apresenta a mesma tendência internacional já relatada pela literatura pertinente. A maioria da população universitária, em nível de graduação, é feminina, porém, na maioria dos cursos do grupo STEM, as mulheres têm reduzida participação, especialmente nas engenharias e nas ciências da computação. Portanto, embora não haja qualquer forma aparente de incentivo ou coerção, as escolhas das carreiras universitárias ainda resultam numa certa especialização por gênero na universidade, o que acaba se refletindo no mercado de trabalho.

Para investigar aspectos de atuação no mercado de trabalho, o artigo apresentou um agrupamento de códigos de ocupação $\mathrm{CBO}$, no qual encontram-se os empregados que constituem a força de trabalho STEM, de acordo com critérios internacionalmente estabelecidos. A participação da força de trabalho STEM, no Brasil, é de 0.24\%, muito inferior à americana, que é de 5\%. Porém, essa participação varia muito ao longo do território nacional. No Estado de Santa Catarina, a proporção STEM também é inferior a 1\%, mas fica claro o perfil econômico de alguns municípios enquanto polos tecnológicos. Em Florianópolis, Blumenau e Joinville, a proporção STEM da força de trabalho local é de 28\%, $14 \%$ e $10 \%$, respectivamente $40 \%$.

Já em termos do perfil de gênero da força de trabalho STEM, há uma homogeneidade em todo o Brasil e no Estado de Santa Catarina. A participação feminina no grupo de ocupações STEM é menor do que 25\%. Além disso, o grau de escolaridade do grupo STEM, em Santa Catarina, é consideravelmente maior do que o do restante do mercado de trabalho. 
Já as medidas de vantagem salarial do trabalho STEM, em Santa Catarina, apresentam algumas especificidades regionais.

Quando se comparam trabalhadores com mesmas características de idade, escolaridade e tempo no emprego, há pouca diferença entre homens e mulheres na média do Estado de Santa Catarina: os homens STEM recebem, em média, 62\% a mais do que os homens Não STEM e as mulheres, 64\% a mais do que a mulheres Não STEM. Esse resultado se alinha ao que tem sido observado internacionalmente, mas não é sempre observado em algumas regiões específicas.

Nos três grandes polos tecnológicos do Estado - Florianópolis, Blumenau e Joinville -, não há muita discrepância entre o prêmio salarial STEM dos homens e das mulheres. Mas, nas regiões com menor participação STEM no mercado de trabalho, surgem as maiores diferenças entre homens e mulheres.

Em Chapecó ocorre a maior diferença entre a vantagem salarial STEM das mulheres e dos homens: respectivamente, $70 \%$ e 30\%. Nos municípios de Lages e Criciúma, embora as mulheres do grupo STEM recebam média salarial maior do que as mulheres Não STEM, ocorre o oposto entre homens STEM e Não STEM.

A explicação poderia estar em variáveis determinantes de médias salariais que não estão incluídas no modelo estimado, como, o fato de a cidade ser ou não um polo tecnológico já estabelecido e a presença/ausência de cursos de formação nas áreas STEM. Em Lages, por exemplo, menos de $1 \%$ da força de trabalho está nas atividades STEM, mas a região abriga centros universitários com oferta de cursos de formação STEM, e, nessas áreas, a população universitária é majoritariamente masculina. Portanto, esses fatores podem indicar o porquê do prêmio STEM masculino ser negativo no município de Lages.

\section{REFERÊNCIAS BIBLIOGRÁFICAS}

ACOLA, Australian Council of Learned Academy. STEM: Countries Comparison. International Comparisons of Science Technology Engeneering and Mathematics (STEM) Education, 2013.

BARRO, R. J.; LEE, J. "International Data on Educational Attainment: Updates and Implications". Oxford Economic Papers, v. 53, n. 3, jul, 2000.

BECKER, G. “Human capital”. 2nd ed. New York: Columbia University Press, 1975. 
BEEDE, D.; JULIAN, T.; LANGDON, D.; MCKITTRICK, G., KHAN, K.; DOMS, M. "Women in STEM: a gender gap to innovation. Executive Summary". US Department of Commerce, Economics and Statistics Administration (ESA), Issue Brief, 2011.

CBO, Classificação Brasileira de Ocupações. Disponível em http://www.ocupacoes.com.br/tabela-completa-da-cbo. Acessado em/08/2018.

EUROMONITOR: International Report. Students of Tomorrow Global Trends Driving Demand for Education, 2018.

FEDGAZZET REGIONAL BUSINESS \& ECONOMICS NEWSPAPER: "Getting to the Root of STEM". The Federal Reserve Bank of Mineapolis, 2014.

GIUBERTI, A.C.; MENEZES-FILHO. N. "Discriminação de Rendimentos por Gênero: uma comparação entre o Brasil e os Estados Unidos”. Economia Aplicada, v. 8, n 3, p. 369-383, 2005.

GOLDBERG, J.D.; HILL,C. "Behind the Paying Gap”. AAUW Educational Foundation. Washington: DC, 2007.

GOLDIN, C. "The quiet revolution that transformed women's employment, education and Family". NBER, working paper, n. 11953, Cambridge, MA, 2006.

HALVORSEN, R.; PALMQUIST, R. "The interpretation of dummy variables in semilogarithmic equations”. The American Economic Review, v. 70, n.3, p. 474-475, 1980.

INEP, Instituto Nacional de Estudos e Pesquisas Educacionais Anisio Teixeira. Censo da Educação Superior, 2015. Disponível em http://portal.inep.gov.br/microdados. Acessada em $1 / 08 / 2018$.

JANN, B. "The Blinder-Oaxaca decomposition for linear regression models". The Stata Journal, v. 8, n. 4, pp. 453-479, 2008.

LANGDON, D.; MCKITTRICK, G.; BEEDE, D., KHAN, B.; DOMS, M. Good Jobs now and for the future. Economic \& Statistic Administration - US Department of Commerce, 2011. (Disponível em http://www.esa.doc.gov/Reports/stem-good-jobs-now-and-future. Acesso em 1/08/2018. 
OAXACA, R.; RANSOM, M. "On discrimination and the decomposition of wage differentials". Journal of Econometrics, v. 61, n. 1, mar, p.5-21, 1994.

OAXACA, R. "Male-female wage differentials in urban labor markets". International Economic Review, v. 62, n. 1, p. 693-709, 1973.

RAIS, Relação Anual de Informação Social. Disponível em http://ftp.mtps.gov.br/pdet/microdados/RAIS/2015. Acessado em 1/08/2018.

RESTUCCIA, D.; VANDENBROUCKE, G. "The Evolution of Education: A Macroeconomic Analysis". University of Toronto, Department of Economics - working paper $388,2010$.

ROMER, P. M. "Endogenous Technological Change”. Journal of Political Economy, v. 98, n. 5, pp. S71-S102, 1990.

ROTHWELL, J. “The Hidden STEM Economy”. The Metropolitan Policy Program at Brookings, 2013. 


\section{APÊNDICE A - CÓDIGOS DE ÁREA ESPECÍFICA, ESTABELECIDOS PELA CLASSIFICAÇÃO OCDE E UTILIZADOS PELO BANCO DE DADOS DO INEP}

Quadro 1 - Classificações STEM: Os códigos de 42 a 62

\begin{tabular}{|c|c|c|}
\hline \multicolumn{2}{|r|}{ Código OCDE } & Cursos existentes em Santa Catarina \\
\hline 14 & $\begin{array}{l}\text { Formação de professor e Ciências da } \\
\text { Educação }\end{array}$ & \\
\hline 21 & Artes & \\
\hline 22 & Humanidades e Letras & \\
\hline 31 & Ciências Sociais e Comportamentais & \\
\hline 32 & Jornalismo e Informação & \\
\hline 34 & Comércio e Administração & \\
\hline 38 & Direito & \\
\hline 42 & Ciências & $\begin{array}{l}\text { Administração de redes, Agrimensura, } \\
\text { Agronomia, Análise e Desenvolvimento de }\end{array}$ \\
\hline 44 & Ciências Físicas & $\begin{array}{l}\text { Sistemas (Tecnólogo), Aquicultura, Arquitetura } \\
\text { e Urbanismo, Automação Industrial, Banco de }\end{array}$ \\
\hline 46 & Matemática e Estatística & $\begin{array}{l}\text { Dados, Biomedicina, Bioquímica Industrial, } \\
\text { Cerâmica Industrial, Ciência da Computação, } \\
\text { Ciências Agrárias, Ciências Biológicas, }\end{array}$ \\
\hline 48 & Computação & $\begin{array}{l}\text { Construção de Edificações, Construção Naval, } \\
\text { Distribuição de Energia Elétrica, Engenharia }\end{array}$ \\
\hline 52 & $\begin{array}{l}\text { Engenharias e profissões } \\
\text { correlatas }\end{array}$ & $\begin{array}{l}\text { Aeroespacial, Engenharia Ambiental, } \\
\text { Engenharia Ambiental e Sanitária, Engenharia } \\
\text { Automotiva, Engenharia Civil, Engenharia de } \\
\text { Alimentos. Engenharia de Comnutacão. }\end{array}$ \\
\hline 54 & Produção e Processamento & $\begin{array}{l}\text { Engenharia de Controle e Automação, } \\
\text { Engenharia de Materiais, Engenharia de Pesca, } \\
\text { Engenharia de Produção, Engenharia de }\end{array}$ \\
\hline 58 & Arquitetura e Construção & Produção de Materiais, Engenharia de \\
\hline 62 & $\begin{array}{l}\text { Agricultura, florestas e recursos } \\
\text { pesqueiros }\end{array}$ & $\begin{array}{l}\text { Telecomunicações, Engenharia Elétrica, } \\
\text { Engenharia Eletrônica, Engenharia Florestal, }\end{array}$ \\
\hline
\end{tabular}




\begin{tabular}{|c|c|c|}
\hline & & $\begin{array}{l}\text { Engenharia Mecânica, Engenharia Mecatrônica, } \\
\text { Engenharia Metalúrgica, Engenharia Naval, } \\
\text { Engenharia Química, Engenharia Sanitária, } \\
\text { Fabricação de Móveis, Física, Geografia } \\
\text { (natureza), Geologia, Indústria do Vestuário, } \\
\text { Indústria Têxtil, Manutenção Industrial, } \\
\text { Matemática, Meteorologia, Oceanografia, } \\
\text { Produção Industrial, Química, Química } \\
\text { Industrial, Sistemas de Informação, Sistemas } \\
\text { Eletrônicos (Experimental), Tecnologia da } \\
\text { Informação, Tecnologia de Alimentos, } \\
\text { Tecnologia Digital, Tecnologia em Agronegócio, } \\
\text { Tecnologia em Desenvolvimento de Softwares, } \\
\text { Tecnologia Química, Telecomunicações, Uso da } \\
\text { Internet, Zootecnia }\end{array}$ \\
\hline 64 & Veterinária & \\
\hline 72 & Saúde & \\
\hline 76 & Serviço Social & \\
\hline 81 & Serviços Pessoais & \\
\hline 84 & Serviços de transporte & \\
\hline 85 & Proteção Ambiental & \\
\hline 86 & Serviços de segurança & \\
\hline
\end{tabular}

Fonte: elaboração a partir do INEP. 
Quadro 2 - Cursos encontrados em Santa Catarina classificados como Não STEM

\begin{tabular}{|c|c|}
\hline \multicolumn{2}{|c|}{ Cursos Não STEM } \\
\hline Administração & História \\
\hline Administração Pública & Hotelaria \\
\hline Agronegócio & Inter. Ind. em Ciências Sociais \\
\hline Agronomia & Inter. Ind. em Línguas, Artes e Literatura \\
\hline Arquitetura e Urbanismo & Inter. Indígena em Pedagogia \\
\hline Arquivologia & $\begin{array}{l}\text { Interd. em Educação do Campo: Ciências da } \\
\text { Natureza }\end{array}$ \\
\hline Arte e Educação & $\begin{array}{l}\text { Interd. em Educação do Campo: Ciências } \\
\text { Sociais }\end{array}$ \\
\hline Artes & Interdisciplinar em Mobilidade \\
\hline Artes Cênicas & Jornalismo \\
\hline Artes Visuais & Letras Alemão \\
\hline Banco de Dados & Letras Espanhol \\
\hline Biblioteconomia & Letras Francês \\
\hline Cerâmica & Letras Inglês \\
\hline Cerâmica e Vidro & Letras Italiano \\
\hline Ciência e Tecnologia de Alimentos & Letras Libras \\
\hline Ciências Agrícolas & Letras Português \\
\hline Ciências Contábeis & Letras Português e Espanhol \\
\hline Ciências da Religião & Letras Português e Inglês \\
\hline Ciências Econômicas & Logística \\
\hline Ciências Naturais & Manutenção Industrial \\
\hline Ciências Rurais & Marketing \\
\hline Ciências Sociais & Medicina \\
\hline Cinema & Medicina Veterinária \\
\hline Cinema e Audiovisual & Mídia Eletrônica \\
\hline Comércio Exterior & Multimídia Digital \\
\hline Comunicação Institucional & Museologia \\
\hline Comunicação Social & Música \\
\hline Construção de Edifícios & Música - Piano \\
\hline
\end{tabular}




\begin{tabular}{|c|c|}
\hline Construção Naval & Música - Violão \\
\hline Cosmetologia e Estética & Música - Violino E Viola \\
\hline Design & Música - Violoncelo \\
\hline Design de Animação & Naturologia Aplicada \\
\hline Design de Interiores & Negócios Imobiliários \\
\hline Design de Moda & Nutrição \\
\hline Design de Produto & Odontologia \\
\hline Design Gráfico & Optometria \\
\hline Design Industrial & Pedagogia \\
\hline Direito & Processos Gerenciais \\
\hline Educação do Campo & Produção Audiovisual \\
\hline Educação Especial & Produção De Vestuário \\
\hline Educação Física & Produção Moveleira \\
\hline Eletrônica Industrial & Produção Multimídia \\
\hline Enfermagem & Produção Publicitária \\
\hline Eventos & Produção Têxtil \\
\hline Fabricação Mecânica & $\begin{array}{l}\text { Programa de Formação Pedagógica De } \\
\text { Docentes }\end{array}$ \\
\hline Filosofia & Psicologia \\
\hline Fisioterapia & Publicidade E Propaganda \\
\hline Fonoaudiologia & Radiologia \\
\hline $\begin{array}{l}\text { Formação de Docentes para a Educação } \\
\text { Básica }\end{array}$ & Relações Internacionais \\
\hline $\begin{array}{l}\text { Formação Específica em Construção de } \\
\text { Edifícios }\end{array}$ & Relações Públicas \\
\hline Fotografia & Secretariado \\
\hline Gastronomia & Secretariado Executivo \\
\hline Geografia & Secretariado Executivo Bilíngue \\
\hline Geologia & Segurança No Trabalho \\
\hline Gestão Ambiental & Segurança No Trânsito \\
\hline Gestão Comercial & Segurança Pública \\
\hline Gestão da Produção Industrial & Serviço Social \\
\hline
\end{tabular}


http://dx.doi.org/10.5007/2175-8085.2019v22n1p82

\begin{tabular}{|l|l|}
\hline Gestão da Qualidade & Serviços Penais \\
\hline Gestão de Cooperativas & Sistemas da Informação \\
\hline Gestão de Micro e Pequenas Empresas & Sistemas de Telecomunicações \\
\hline Gestão de Recursos Humanos & Sociologia \\
\hline Gestão de Segurança Pública & Teatro \\
\hline Gestão De Turismo & Teologia \\
\hline Gestão Financeira & Terapia Ocupacional \\
\hline Gestão Hospitalar & Transporte Aéreo \\
\hline Gestão Portuária & Turismo \\
\hline Gestão Pública & Viticultura E Enologia \\
\hline
\end{tabular}

Fonte: elaboração a partir do INEP. 
APÊNDICE B - OCUPÇÕES STEM

Quadro 1 - Códigos CNAE-CBO identificados como STEM

\begin{tabular}{|c|c|c|c|c|c|c|}
\hline 142005 & 203025 & 212215 & 213205 & 214245 & 214415 & 214750 \\
\hline 142510 & 203105 & 212305 & 213210 & 214250 & 214420 & 214805 \\
\hline 142515 & 203110 & 212310 & 213215 & 214255 & 214425 & 214810 \\
\hline 142520 & 203115 & 212315 & 213305 & 214260 & 214430 & 214905 \\
\hline 142525 & 203120 & 212320 & 213310 & 214265 & 214435 & 214910 \\
\hline 142530 & 203125 & 212405 & 213315 & 214270 & 214505 & 214915 \\
\hline 142535 & 203205 & 212410 & 213405 & 214275 & 214510 & 214920 \\
\hline 142605 & 203210 & 212415 & 213410 & 214280 & 214515 & 214925 \\
\hline 142610 & 203215 & 212420 & 213415 & 214305 & 214520 & 214930 \\
\hline 201105 & 203220 & 213105 & 213420 & 214310 & 214525 & 214935 \\
\hline 201110 & 203225 & 213110 & 213425 & 214315 & 214530 & 214940 \\
\hline 201115 & 203230 & 213115 & 213430 & 214320 & 214535 & 221105 \\
\hline 201205 & 203405 & 213120 & 213435 & 214325 & 214605 & 221205 \\
\hline 201210 & 203410 & 213125 & 213440 & 214330 & 214610 & 222105 \\
\hline 201215 & 203415 & 213130 & 214005 & 214335 & 214615 & 222110 \\
\hline 201220 & 203420 & 213135 & 214010 & 214340 & 214705 & 222115 \\
\hline 201225 & 211110 & 213140 & 214205 & 214345 & 214710 & 222120 \\
\hline 202105 & 211115 & 213145 & 214210 & 214350 & 214715 & 222205 \\
\hline
\end{tabular}


http://dx.doi.org/10.5007/2175-8085.2019v22n1p82

\begin{tabular}{|l|l|l|l|l|l|l|}
\hline 202110 & 211120 & 213150 & 214215 & 214355 & 214720 & 222215 \\
\hline 202115 & 211205 & 213155 & 214220 & 214360 & 214725 & 203015 \\
\hline 202120 & 211210 & 213160 & 214225 & 214365 & 214730 & 203010 \\
\hline 203005 & 211215 & 213165 & 214230 & 214370 & 214735 & 212205 \\
\hline 213170 & 214235 & 214405 & 214740 & & & \\
\hline
\end{tabular}

Fonte: elaboração a partir da CBO. 
http://dx.doi.org/10.5007/2175-8085.2019v22n1p82

\section{APÊNDICE C - RESULTADOS DA ANÁLISE DE REGRESSÃo}

Tabela 1 - Coeficientes ${ }^{1}$ estimados para o prêmio salarial STEM e respectivos $\mathrm{P}$-Valor

Homens

Mulheres

\begin{tabular}{ccccc}
\hline & Coeficiente & P-Valor & Coeficiente & P-Valor \\
\hline Florianópolis & 0.470699 & 0 & 0.460757 & 0 \\
Blumenau & 0.540133 & 0 & 0.476055 & 0 \\
Criciúma & -0.20917 & 0.053 & 0.353794 & 0 \\
& & & & \\
Joinville & 0.490278 & 0 & 0.394486 & 0 \\
& & & & 0 \\
Chapecó & 0.260871 & 0.001 & 0.529089 & 0 \\
& & & & 0 \\
\hline Lages & -0.44943 & 0.293 & 0.529628 & 0 \\
& & & & 0.484527 \\
\hline Estado SC & 0.483171 & 0 & 0
\end{tabular}

$1 \mathrm{O}$ modelo ajustado é semilogarítmico e a variável de ocupação STEM é binária. Então, seguindo a sugestão de Harvorsen e Palmquist (2010), a interpretação de um coeficiente estimado, c, não é direta, mas feita em termos do antilog de c. O salário do grupo STEM é $[100 x(\exp (\mathrm{c})-1)] \%$ maior (se c $>0)$ ou menor $($ se $\mathrm{c}<0)$ do que o salário do grupo base de comparação, no caso, Não STEM. O que se tem, nesse caso, é uma comparação entre medianas, em vez de médias. Assim, de acordo com a Tabela 1, a mediana do salário dos homens do grupo STEM em Florianópolis é 100x(exp(0.470699)-1=60,1113\% maior do que a mediana do dos homens Não STEM. No gráfico da Figura 8, o salário do homem Não STEM é R\$ 100, enquanto o do homem STEM é R\$ 162. 
Tabela 2 - Coeficientes estimados para variáveis explicativas da média salarial feminina

\begin{tabular}{cccccccc}
\hline \multicolumn{7}{c}{ Localidade } \\
\hline Var & Blu & Flo & Join & Cric & Lag & Chap & Santa \\
& & & & & & & Catarina \\
Idade & 0.030536 & 0.0304 & 0.024697 & 0.024102 & 0.009356 & 0.028626 & 0.044346 \\
Idade2 & -0.00037 & -0.00038 & -0.00033 & -0.0003 & -0.00013 & -0.00035 & -0.00049 \\
exper & 0.002764 & 0.003535 & 0.003516 & 0.003394 & 0.002903 & 0.002807 & 0.002959 \\
sup & 0.751795 & 0.975721 & 0.710542 & 0.852562 & 0.653913 & 0.755319 & 0.858627 \\
mes & 1.666 .543 & 1.333 .601 & 139.726 & 1.520 .637 & 1.447 .404 & 1.451 .639 & 1.433 .396 \\
dout & 1.596 .442 & 1.678 .683 & 1.505 .408 & 1.495 .286 & 1.888 .612 & 1.782 .959 & 1.558 .017 \\
stem & 0.476055 & 0.460757 & 0.490278 & 0.353794 & 0.529628 & 0.529089 & 0.481881 \\
cons & 2.831 .667 & 284.591 & 2.942 .878 & 2.853 .013 & 3.093 .601 & 2.821 .075 & 2.645 .611 \\
\hline
\end{tabular}

Tabela 3 - Coeficientes estimados para as variáveis explicativas da média salarial masculina

\begin{tabular}{cccccccc}
\hline \multicolumn{7}{c}{ Localidade } \\
\hline Var & Blu & Flo & Join & Cric & Lag & Chap & Santa \\
& & & & & & & Catarina \\
Idade & 0.048429 & 0.048781 & 0.052069 & 0.044773 & 0.036593 & 0.051591 & 0.021227 \\
Idade2 & -0.00054 & -0.00052 & -0.00061 & -0.00051 & -0.00041 & -0.00056 & -0.00026 \\
exper & 0.003041 & 0.003025 & 0.003225 & 0.003502 & 0.00239 & 0.002409 & 0.003022 \\
sup & 0.802708 & 0.984505 & 0.766117 & 0.814008 & 0.686119 & 0.747027 & 0.838154 \\
mes & 1.581 .061 & 1.369 .336 & 1.468 .507 & 1.397 .501 & 1.178 .271 & 1.260 .174 & 1.510 .494 \\
dout & 1.398 .293 & 1.628 .586 & 1.437 .852 & 1.552 .734 & 1.561 .656 & 1.622 .437 & 1.718 .327 \\
stem & 0.540133 & 0.470699 & 0.394486 & -0.20917 & -0.44943 & 0.260871 & 0.497321 \\
cons & 2.596 .222 & 2.586 .514 & 2.585 .104 & 2.653 .781 & 2.711 .349 & 2.546 .402 & 2.937 .154 \\
\hline
\end{tabular}

